\title{
FREQUENCY OF CLINICAL FEATURES AND CYTOGENETIC DEFECTS IN DOWN SYNDROME DIAGNOSED AT AFIP
}

\author{
Saira Irum, Helen Mary Robert, Asad Mahmood, Rafia Mahmood, Ayesha Khurshid, Saleem Ahmed Khan \\ Armed Forces Institute of Pathology/National University of Medical Sciences (NUMS) Rawalpindi Pakistan
}

\begin{abstract}
Objective: To determine the frequency of clinical features and cytogenetic abnormalities in patients of down syndrome and correlation of cytogenetic abnormalities with clinical features.

Study Design: Cross sectional study.

Place and Duration of Study: Department of Haematology, Armed Forces Institute of Pathology, Rawalpindi, from Feb 2017 to Feb 2018.

Methodology: Total 163 patients with clinical suspicion of Down syndrome were selected by non-probability convenient sampling and diagnosis was confirmed by conventional cytogenetic analysis using Giemsa trypsin banding technique. Clinical features were assessed and frequency of different cytogenetic abnormalities were noted.

Results: Out of total 163 patients, $96(59 \%)$ were male and $67(41 \%)$ were female. Median age of the patients was 11 months. Trisomy 21 was detected in 158 (96.9\%), Robertsonian translocation in $4(2.4 \%)$ and mosaicism in 01 $(0.6 \%)$ patient. The predominant clinical features observed were slaunted with eyes, epicanthic folds, depressed nasal bridge and protruding tongue.

Conclusion: Trisomy 21 is the most common cytogenetic abnormality observed in patients of down syndrome.

Keywords: Down syndrome, Karyotyping, Trisomy 21.

This is an Open Access article distributed under the terms of the Creative Commons Attribution License (http://creativecommons.org/licenses/by/4.0), which permits unrestricted use, distribution, and reproduction in any medium, provided the original work is properly cited.
\end{abstract}

\section{INTRODUCTION}

Down syndrome is the most common autosomal abnormality and an important genetic cause of intellectual disability 1 . Its incidence is about 1 in 700 live born infants ${ }^{2}$. Down syndrome is caused by three types of chromosomal abnormalities; trisomy 21, translocation and mosaic trisomy ${ }^{3}$. Trisomy 21 is observed in over $95 \%$ of patients, translocation in $2-4 \%$ and mosaicism in $1-2 \%$ of patients ${ }^{4}$.

Trisomy 21 occurs due to nondisjunction of chromosome 21 during gametogenesis in one of the parents or during post zygotic mitosis in early embryonic development. Nondisjunction occurs most commonly during gamete formation process in females than in males. Nondisjunction of chromosomes during post zygotic mitosis in early embryonic development occurs in $>5 \%$ of cases ${ }^{5}$. Exact cause of nondisjunction is not known but

Correspondence: Dr Saira Iram, Dept of Haematology, Armed Forces Institute of Pathology, Rawalpindi Pakistan

Received: 29 Jan 2019; revised received: 19 May 2019; accepted: 28 May 2019 advanced maternal age is an important risk factor for maternal meiotic nondisjunction ${ }^{6}$.

In Robertsonian translocation, extra chromosome 21 is translocated to acrocentric chromosome of $G$ group (chromosome 21, 22) or D group (chromosome 13,14,15). The most common type is non homologous Robertsonian translocation between chromosome 14 and 21 and second most common type is homologous Robertsonian translocation between chromosome 21 and 217. It can occur spontaneously de novo during gametogenesis in one of the parents or can be inherited from carrier parents. In the case of Robertsonian translocation created sporadically de novo, the risk to second offspring is small. When one parent is carrier of $21 q 21 q$ Robertsonian translocation, the risk to second offspring is $100 \%$ as all of its produced gametes are unbalanced ${ }^{8}$.

In moscaic trisomy 21 patient has two cell lines, one with 46 Chromosomes having normal karyotype and the other with 47 chromosomes 9 . These individuals may be phenotypically less affected 7 . 
The characteristics features of Down syndrome are facial features (mongoloid face, depressed nasal bridge, hypertelorism), simian crease, brachycephaly, short stature and hypotonia. Patients with Down syndrome have increased risk of congenital heart defects, genitourinary, gastrointestinal, skeletal, haematological and other medical disorders ${ }^{10}$.

Cytogenetics is an important technique for diagnosis of Down syndrome ${ }^{11}$. It is also important for determining recurrent risk and advising genetic counseling ${ }^{12}$. In case of Robertsonian translocation; if parent is also carrier of Robertsonian translocation, the risk to next offspring is high. But this technique is only available in few centres in our country. Most of the data regarding the fre-quency of cytogenetic abnormalities and clinical features of Down syndrome is from Western Studies but limited data is available from our region. So, we conducted this study with the aim to determine the frequency of different cytogenetic abnormalities in Down syndrome to help clinicians to counsel patients regarding the recurrence risk.

\section{METHODOLOGY}

This was a cross sectional study conducted in the Department of Haematology, Armed Forces Institute of Pathology Rawalpindi, from Feb 2017 to Feb 2018. All patients with clinical suspicion of Down syndrome irrespective of age and gender were selected by convenient non-probability sampling. Sample size was 163 . Patients with haematological malignancy having trisomy 21 were excluded.

Study was conducted after the ethical approval of the institutional review board. All individuals were included in this study after informed consent of their parents. Detailed history was taken and physical examination was carried out and findings were recorded in pre-designed performa.

Cytogenetic analysis was performed to confirm the diagnosis by using conventional $G$ banding technique. 3-5 $\mathrm{ml}$ of heparinized blood sample was taken. Samples were cultured in RPMI
1640 medium for 72 hrs. Harvesting was done to obtain metaphases by first adding $1 \%$ colchicine followed by incubation, centrifugation and addition of hypotonic solution of $1 \% \mathrm{KCl}$. After addition of fixative (3:1 methanol to glacial acetic acid) slides were made and examined under microscope after Leishmann staining to look for presence of at least 20 metaphases which rendered culture successful. Giemsa trypsin banding was performed and slides were analyzed by Cytovision semi-automated image analysis and capture system.

SPSS 24 was used for analysis. Quantitative variables were presented in terms of median while qualitative variables by frequency and percentage.

\section{RESULTS}

A total of 163 patients with clinical suspicion of Down syndrome confirmed on Cytogenetic analysis were included in the study. Of these $96(59 \%)$ patients were male and $67(41 \%)$ were female. The median age of the enrolled patients

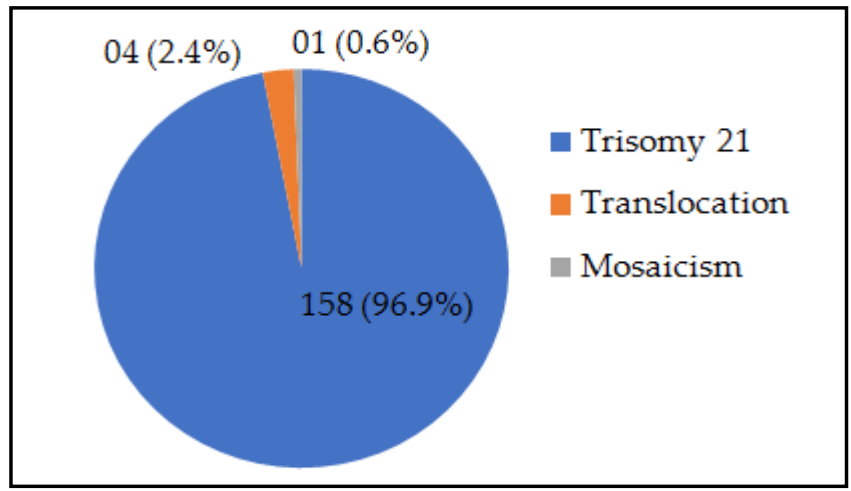

Figure: Different cytogenetic abnormalities in patients of down syndrome.

was 11 months.

The cytogenetic analysis showed that trisomy 21 was the most common abnormality and detected in 158 patients (96.9\%), 4 (2.4\%) patients had Robertsonian translocation and only 1 (0.6\%) patient was shown to have mosaicism. In patients with Robertsonian translocation; chromosome 21 was translocated to chromosome ${ }^{14}$.

The clinical features observed in patients of Down syndrome are listed in table. 
The predominant clinical features noted were slanted eyes, epicanthic folds and depressed nasal bridge.

Table: Frequency of clinical features in patients of down syndrome $(n=163)$.

\begin{tabular}{|c|c|c|c|c|}
\hline 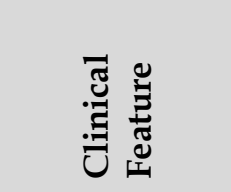 & 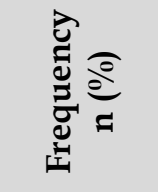 & 总 & 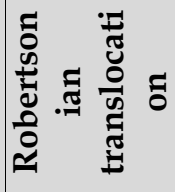 & 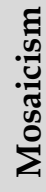 \\
\hline Slanted eyes & $\begin{array}{c}121 \\
(74.2)\end{array}$ & 118 & 3 & - \\
\hline $\begin{array}{l}\text { Depressed } \\
\text { nasal bridge }\end{array}$ & $\begin{array}{c}115 \\
(70.5)\end{array}$ & 111 & 3 & 1 \\
\hline $\begin{array}{l}\text { Epicanthic } \\
\text { folds }\end{array}$ & $95(58.2)$ & 92 & 3 & - \\
\hline $\begin{array}{l}\text { Protruding } \\
\text { tongue }\end{array}$ & $84(51.5)$ & 82 & 2 & - \\
\hline Sandal gap & 73 (44.7) & 70 & 3 & - \\
\hline Flat occiput & $69(42.3)$ & 66 & 2 & 1 \\
\hline $\begin{array}{l}\text { Transverse } \\
\text { palmer crease }\end{array}$ & $59(36.1)$ & 57 & 2 & - \\
\hline $\begin{array}{l}\text { Congenital } \\
\text { heart disease }\end{array}$ & 55 (33.7) & 54 & 1 & - \\
\hline $\begin{array}{l}\text { Respiratory } \\
\text { infections }\end{array}$ & $53(32.5)$ & 51 & 1 & 1 \\
\hline $\begin{array}{l}\text { Dysplastic } \\
\text { ears }\end{array}$ & $23(14.1)$ & 23 & - & - \\
\hline $\begin{array}{l}\text { Umbilical } \\
\text { hernia }\end{array}$ & $14(8.5)$ & 14 & - & - \\
\hline
\end{tabular}

\section{DISCUSSION}

Down syndrome is the most common birth defect and common cause of mental retardation. Though strong clinical suspicion favours the diagnosis but cytogenetic studies are essential to confirm the clinical diagnosis. The particular karyotype has little if, any effect on clinical presentation but it helps in determining recurrence risk. However, facilities for cytogenetic analysis are available only in few centres in Pakistan resulting in delay in diagnosis in some patients.

The median age in our study was 11 months. Male to female ratio was 1.4:1. The predominance of males appears to be universal and reported by many studies and ranged from 1.1:1 to 2.3:1.13 Study conducted by Ahmed et al (Pakistan), Jaouad et al (Morocco) and Hirak et al (India) also reported male to female ratio of 1.3:114,15,8. However, study conducted in Iraq by Salih et al showed female predominance among Down syndrome patients ${ }^{16}$.

Cytogenetic studies in patients with Down syndrome carried out in different countries have shown differences in frequencies of these abnormalities. The cytogenetic abnormalities observed in our study are trisomy $21(96.9 \%)$, translocation $(2.4 \%)$ and mosaicism $(0.6 \%)$. Similar results are seen in many other studies like Mokhtar et al (Egypt) reported trisomy 21 (95.4\%), translocation $(2.7 \%)$ and mosaicism $(0.7 \%)^{17}$. El Gilany et al reported trisomy $21(96.1 \%)$, translocation (3.1\%) and mosaicism $(0.8 \%)^{13}$. Jaouad et al from Morocco reported trisomy $21(96.2 \%)$, translocation $(3.1 \%)$ and mosaicism $(0.5 \%)^{15}$. However study conducted by Salih et al in the Iraqi population has reported higher frequency of translocations as being $5.8 \%{ }^{16}$. Similar results have been reported by Pankaj et al in the Indian children ${ }^{18}$. Chandra et al (India) in a study conducted at Department of Genetics, University of Madras has observed mosaicism in $10.7 \%$ of his population which is quite higher than other studies ${ }^{19}$.

The predominant clinical features observed in present study are slanted eyes, epicanthic folds, depressed nasal bridge. Study conducted by Ahmed et al also reported high frequency of these clinical features ${ }^{14}$. The frequency of Simian crease and sandal gap in our study was 36.2\% and $44.8 \%$ respectively. Similar results were reported by study conducted by Kava et al20.

\section{CONCLUSION}

Trisomy 21 is the most common cytogenetic abnormality observed in patients of Down syndrome. Patients with mosaic Down syndrome are mildly affected. Identification of specific types of chromosomal abnormalities is important as it can help clinicians to counsel the parents regarding the recurrence risk.

\section{CONFLICT OF INTEREST}

This study has no conflict of interest to declare by any author. 


\section{REFERENCES}

1. Belmokhtar F, Belmokhtar R, Kerfouf A. Cytogenetic study of down syndrome in Algeria: Report and review. J Med Sci 2016; 36(2): 46-52.

2. Crombag NM, Boeije H, Iedema-Kuiper R, Schielen PC, Visser $\mathrm{GH}$, Bensing JM. Reasons for accepting or declining Down syndrome screening in Dutch prospective mothers within the context of national policy and healthcare system characteristics: a qualitative study. BMC Pregnancy Childbirth 2016; 16(1): 121.

3. Verma IC, Lall M, Puri RD. Down syndrome in India - Diagnosis, screening, and prenatal diagnosis. Clin Lab Med 2012; 32(2): 231-48.

4. Podder G, De A, Adhikari A, Halder A, Banerjee J, De M. Assesment of down syndrome patients in West Bengal, India. Pacific J Med Sci 2013; 10(2): 28-35.

5. Kolgeci S, Kolgeci J, Azemi M, Shala-Beqiraj R, Gashi Z, Sopjani M. Cytogenetic study in children with Down syndrome among Kosova Albanian population between 2000 and 2010. Materia Socio Medica 2013; 25(2): 131.

6. Kurtovic-Kozaric A, Mehinovic L, Malesevic R, Mesanovic S, Jaros T, Stomornjak-Vukadin M, et al. Ten-year trends in prevalence of down syndrome in a developing country: impact of the maternal age and prenatal screening. Eur J Obs Gynecol Reprod Biol 2016; 206: 79-83.

7. Jayalakshamma, Margaret M, Amudha S, Tilak P, Devi R, Rajangam S. Cytogenetic analysis in Down syndrome. Intl J Human Genetics 2010; 10(1-3): 95-99.

8. Hirak D, Giriraj K, Priyanka S, Tulika N, Rita P, Arpita G. Study of the frequency of down syndrome in a north east Indian Population. Int J Med Res Health Sci 2015; 4(4): 799-802.

9. Asim A, Kumar A, Muthuswamy S, Jain S, Agarwal S. Down syndrome: an insight of the disease. J Bio Med Sci 2015; 22(1): 41.

10. Akın F, Yazar A, Türe E. Retrospective evaluation of 214 cases of down syndrome. Haydarpasa Numune Med J 2018; 58(1): 39-44.

11. Daimei T, Sinam V, Singh TN, Devi ND. Phenotypes and congenital anomalies of down syndrome in Manipur. J Dent Med Sci 2015; 14(5): 1-9.

12. Biselli J, Goloni-Bertollo E, Ruiz M, Pavarino-Bertelli É. Cytogenetic profile of Down syndrome cases seen by a general genetics outpatient service in Brazil. Downs Syndr Res Pract 2008; 12(1): EJ850568.

13. El-Gilany AH, Yahia S, Shoker M, El-Dahtory F. Cytogenetic and comorbidity profile of Down syndrome in Mansoura University Children's Hospital, Egypt. Ind J Human Gene 2011; 17(3): 157.

14. Ahmed I, Ghafoor T, Samore NA, Chattha MN. Down syndrome: clinical and cytogenetic analysis. J Coll Physicians Surg Pak 2005; 15(7): 426.

15. Jaouad I, Deqaqi SC, Sbiti A, Natiq A, Elkerch F, Sefiani A. Cytogenetic and epidemiological profiles of Down syndrome in a Moroccan population: a report of 852 cases. Singapore Med J 2010; 51(2): 133.

16. Salih DJ, Bakir N, Eissa AAA, Al-Allawi NA. Clinical and Cytogenetic Profile in Patients with Down Syndrome in Duhok Province, Iraq. Med J Babylon 2017; 14(2): 389-401.

17. Mokhtar M, Aziz AA, Nazmy N, Mahrous H. Cytogenetic profile of down syndrome in alexandria, Egypt. East Mediterr Health J 2003; 9(1-2): 37-44.

18. Pankaj G, Avani K, Salil V. Prevalence of down syndrome in western India: A Cytogenetic Study. Br J Medicine Medical Res 2015; 5(10): 1255.

19. Chandra N, Cyril C, Lakshminarayana P, Nallasivam P, Ramesh A, Gopinath P, et al. Cytogenetic evaluation of down syndrome: a review of 1020 referral cases. Intl J Human Genetics 2010; 10(13): 87-93.

20. Kava MP, Tullu MS, Muranjan MN, Girisha K. Down syndrome:: Clinical profile from India. Arch Med Res 2004; 35(1): 31-35. 